\title{
CHEMICAL MODIFICATION OF CELLULOSIC MATERIAL USING ALKOXYSILANE/BORIC ACID AND ALKOXYSILANE/PYROGENIC SILICA MATRICES
}

\author{
CHRISTIAN SCHRAMM and ANGELIKA AMANN \\ Research Institute of Textile Chemistry and Textile Physics, University of Innsbruck, \\ Höchsterstrasse 73, A-6850 Dornbirn, Austria \\ Corresponding author: Christian Schramm, christian.schramm@uibk.ac.at
}

\begin{abstract}
Cotton specimens were chemically modified with solutions containing alkoxysilanes (tetraethoxysilane TEOS), (3glycidylpropyl)trimethoxysilane, GPTMS), or (3-triethoxysilyl-propyl)succinic acid anhydride, TESP-SA), in combination with either boric acid or pyrogenic silica. The cotton samples were impregnated with the hydrolyzed alkoxysilane solutions and thermally treated at $160{ }^{\circ} \mathrm{C}$ for $10 \mathrm{~min}$. The physico-mechanical properties (dry crease recovery angle, tensile strength, flexural rigidity, abrasion resistance, air permeability, whiteness index, water vapor permeability) have been evaluated. The samples were analyzed by means of FT-IR and thermal gravimetric analyses (TGA). The morphology of the surface was studied applying confocal laser microscopy. In comparison with the untreated samples, the values of the dry crease recovery angle increased, whereas the tensile strength, flexural rigidity and the whiteness index (WI) decreased.
\end{abstract}

Keywords: cotton, surface modification, sol-gel technique, boric acid, pyrogenic silica

\section{INTRODUCTION}

A cotton-based material is made up of cellulose containing repeating anhydroglucose units (cellobiose). Each of these anhydroglucose units contains two secondary and one primary hydroxyl groups, capable of forming intermolecular or intramolecular hydrogen bonding, which are governing the structural characteristics, as well as the reactivity of the cellulose. ${ }^{1,2}$

Surface modification of textiles with desired functionalities can be engineered by a number of various techniques, ranging from traditional treatments to multifunctional approaches, in an attempt to meet additional requirements for apparel or industrial applications. For this purpose, physical as well as chemical methods are applied, such as the sol-gel process. ${ }^{3-5}$ This process is accomplished by the hydrolysis and subsequent condensation reaction of metal or semimetal alkoxides, such as organosilicates, titanates, -aluminates. As a result, organicinorganic hybrids are produced, which are also of high interest in the field of coating due to their ability to combine the advantages stemming from both the organic group and the inorganic group. ${ }^{6,7}$
The as-prepared solutions, to which various additives can be added, are applied to the textile systems by impregnation and subsequent thermal treatment.

Applying the sol-gel technique, novel properties can be imparted to the cotton-based material, such as crease resistance, ${ }^{8-11}$ abrasion resistance, ${ }^{12}$ water repellency, ${ }^{13,14}$ flame retardency, ${ }^{15-17}$ antimicrobial finishing, ${ }^{18-20}$ drug delivery systems, ${ }^{21,22}$ UV protection, ${ }^{23,24}$ selfcleaning properties ${ }^{25,26}$ and wound healing. ${ }^{27,28}$ In a previous study, a cotton material was functionalized by means of the alkoxysilanes TEOS, GPTMS, and TESP-SA, in combination with the polymers poly(vinylalcohol) (PVA), poly(ethylene oxide) (PEO) and poly(vinylpyrrolidon) (PVP), resulting in improved physico-mechanical properties. ${ }^{29}$

The goal of the present study was to evaluate the physico-mechanical properties of cotton samples impregnated with solutions consisting of hydrolyzed alkoxysilanes (TEOS, GPTMS, TESP-SA) and boric acid or pyrogenic silica. 


\section{CHRISTIAN SCHRAMM and ANGELIKA AMANN}

\section{EXPERIMENTAL \\ Materials}

Tetraethoxysilane (98\%, TEOS) was supplied from Fluka Chemie GmbH, Buchs, Switzerland. (3Glycidylpropyl)trimethoxysilane (100\%, GPTMS) and (3-triethoxysilyl-propyl)succinic acid anhydride (TESP-SA, 100\%) were obtained from Wacker Silicone, Burghausen, Germany. The chemical formula of the trialkoxysilanes can be seen in Figure 1. Boric acid (>99\%) was purchased from Sigma-Aldrich, St. Louis, USA. Pyrogenic silica (Aerosil 380, 100\%) was obtained from Degussa AG, Frankfurt/Main, Germany. The chemicals were applied without further purification. Deionized water (DI) was used throughout the investigation. Desized, scoured, bleached and mercerized $100 \%$ cotton fabric (weave type: plain, density warp: 52 yarn/cm, weft: 24 yarn $/ \mathrm{cm}$, weight: $109 \mathrm{~g} / \mathrm{m}^{2}$ ) was utilized throughout the study.

\section{Preparation of the alkoxysilane solutions}

The finishing solutions were prepared as follows: $15 \mathrm{mmol}$ or $30 \mathrm{mmol}$ of each of the alkoxysilanes (TEOS, GPTMS, TESP-SA) were hydrolyzed in 30 $\mathrm{mL} \mathrm{DI} \mathrm{and} 5 \mathrm{~mL} \mathrm{HCl}(\mathrm{c}=0.1 \mathrm{~mol} / \mathrm{L})$ at room temperature (RT) for $3 \mathrm{~h}$ under stirring in a polypropylene beaker, which was sealed with a pierced parafilm. Then, a solution of boric acid $(2 \mathrm{~g}$ or $4 \mathrm{~g}$ in $50 \mathrm{~mL}$ DI) or a suspension of pyrogenic silica $(0.5 \mathrm{~g}$ or $1 \mathrm{~g}$ in $50 \mathrm{~mL} \mathrm{DI}$ ) was added under stirring for $10 \mathrm{~min}$ at RT. Subsequently, the solutions were filled up to $100 \mathrm{~mL}$ with DI.

\section{Preparation of the cotton samples}

The pre-weighed cotton samples were impregnated with the corresponding alkoxysilane solutions applying a two-roll laboratory padder (HVL 500 Mathis AG, Niederhasli, Switzerland; air pressure 1 bar, rotary speed $3 \mathrm{~m} / \mathrm{min}$ ). The impregnated samples were dried at $105{ }^{\circ} \mathrm{C}$ for $2 \mathrm{~min}$ in a lab dryer (LTE, W. Mathis AG, Switzerland). The condensation reaction was conducted at $160{ }^{\circ} \mathrm{C}$ for $10 \mathrm{~min}$. The preparation scheme is presented in Figure 2. The as-prepared cotton samples were designated as follows: $\mathrm{XX}-\mathrm{XX}-\mathrm{Y}$ - yy. XX refers to the alkoxysilane applied $(\mathrm{TE}=\mathrm{TEOS}$, $\mathrm{GP}=$ GPTMS, TS = TESP-SA); $\mathrm{xx}$ refers to the amount of the alkoxysilane $(\mathrm{xx}=15$ or $30 \mathrm{mmol} / 100$ $\mathrm{mL})$; $\mathrm{Y}$ corresponds to the additive $(\mathrm{B}=$ boric acid, $\mathrm{P}=$ pyrogenic silica), and yy corresponds to the amount of additive (yy $=1$ or $2 \mathrm{~g} / 100 \mathrm{~mL}$ for boric acid; 0.5 or 1 $\mathrm{g} / 100 \mathrm{~mL}$ for pyrogenic silica).

\section{Apparatus and methods}

The add-on of the fabric weight was calculated as follows: add-on $(\%)=\left[\left(\mathrm{W}_{2}-\mathrm{W}_{1}\right) / \mathrm{W}_{1}\right] \times 100 ; \mathrm{W}_{1}$ and $\mathrm{W}_{2}$ are the weights of the fabric specimens before and after the treatment, respectively. The dry crease recovery angle (DCRA) was measured according to ISO 2312: 10 test specimens were creased and compressed under controlled conditions of time and load. After removal of the creasing load, the angle formed between the two limbs was measured. The DCRA values render possible the evaluation of a cross-linking reaction between a crease-resistant finishing agent and the cellulosic material. Tensile strength (TS) was determined with the Material Testing System Z010 (Zwick/Roell, Ulm, Germany) according to DIN EN ISO13934. The stiffness of the fabrics was determined by means of a Taber Stiffness Tester, Model 112, New York, USA, according to ASTM D 1388-R6. Flexural rigidity was calculated as described in ASTM D 1388-R6. Abrasion tests were performed according to DIN EN ISO 12947 (Martindale method). The measurement of the air permeability was conducted according to DIN EN ISO 9237, using the air permeability tester Textest FX 3030 LDM, Textest Ldt, Zurich, Switzerland. Colorimetric data measurements were conducted with the Spectrophotometer CM-3610d from Konica Minolta, Japan. The color data software CM-S100w Spectra Magic NX V1.9 was used for data acquisition.

The water vapor permeability (WVP) was studied gravimetrically by placing disks covered with the cellulosic specimens in a desiccator at air humidity of $100 \%$ at $23{ }^{\circ} \mathrm{C}$ for $96 \mathrm{~h}$. The WVP rate was measured gravimetrically using the water method, following ASTM E96. A plastic cup (4 cm diameter, $2.5 \mathrm{~cm}$ height, $25 \mathrm{~mL})$ was partially filled with DI $(11 \mathrm{~mL})$.<smiles>CCO[Si](OCC)(OCC)OCC</smiles>

Tetraethoxysilane TEOS<smiles>CO[Si](CCCOCC1CO1)(OC)OC</smiles>

(3-Glycidyloxypropyl)trimethoxysilane GPTMS<smiles>CCCC(CCC)OC(=O)CC</smiles>

(3-Triethoxysilylpropyl)succinic acid anhydride TESP-SA

Figure 1: Chemical formula of the compounds of interest 


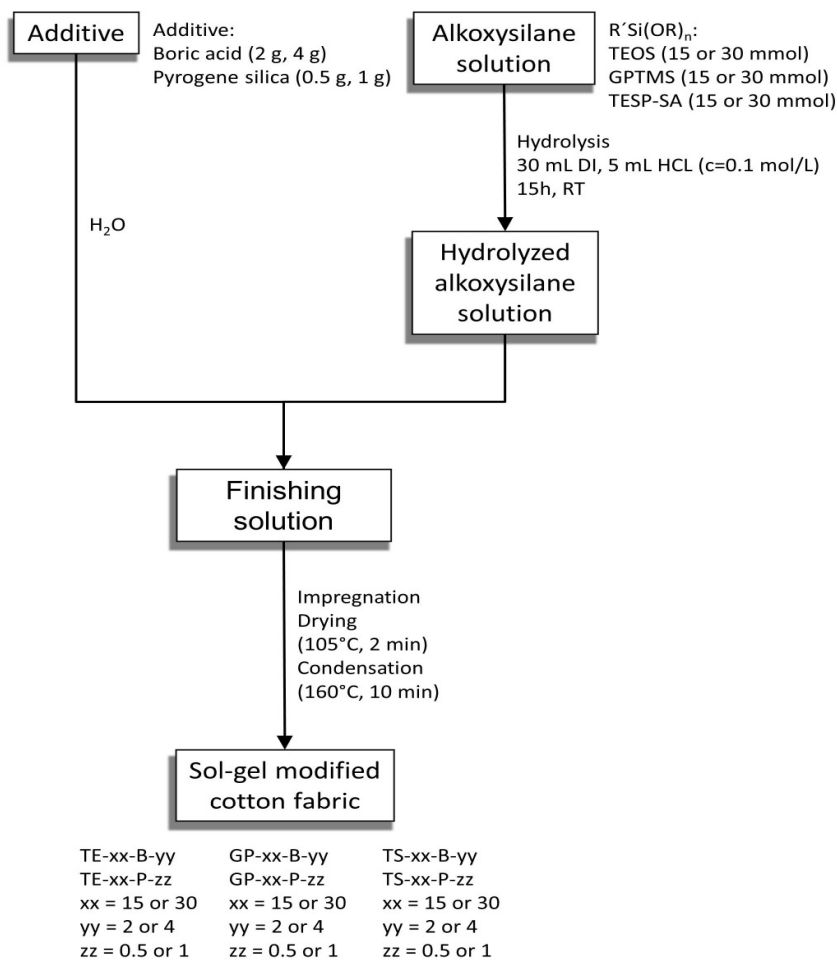

Figure 2: Scheme of the finishing procedures for the preparation of the alkoxysilane/boric acid or pyrogenic silica modified cotton samples

A hole $(1.5 \mathrm{~cm}$ diameter) in the lid of the cup was sealed with the circular test specimen. This cup assembly was placed in a desiccator filled with silica gel. The initial weight of the assembly was taken, and then the assembly was reweighed after $96 \mathrm{~h}$.

FT-IR/ATR spectra were recorded with a Bruker Vector 22 spectrometer, using a DTGS detector. The spectra were the result of 50 scans. The spectral resolution was $4 \mathrm{~cm}^{-1}$. A PIKE MIRacle TM ATR accessory, equipped with a diamond ATR crystal, was used. The surface morphology was studied by means of a 3D laser confocal microscope (Keyence VKX150, Osaka, Japan). TG measurements were conducted with the thermogravimetric analyzer Mettler Toledo TGA 2 Star System (heating rate of $10{ }^{\circ} \mathrm{C} / \mathrm{min}$; scan range of $40-900{ }^{\circ} \mathrm{C}$ ) in air.

\section{RESULTS AND DISCUSSION}

Various aqueous finishing baths containing 15 $\mathrm{mmol} / 100 \mathrm{~mL}$ or $30 \mathrm{mmol} / 100 \mathrm{~mL}$ of TEOS, GPTMS or TESP-SA, in combination with boric acid ( $2 \mathrm{~g}$ or $4 \mathrm{~g}$ ) or pyrogenic silica $(0.5 \mathrm{~g}$ or $1 \mathrm{~g})$, were prepared and subsequently applied to a cotton sample by an impregnation, drying and curing process in an attempt to obtain a permanent fixation of the chemical agents on the cotton fabric. The physico-mechanical properties of the as-prepared samples were evaluated.

\section{Evaluation of process parameters}

To figure out the optimum curing temperature, various cotton samples were impregnated with various alkoxysilane/boric acid or pyrogenic silica-containing finishing baths and were thermally treated at different temperatures (120 ${ }^{\circ} \mathrm{C}, 140{ }^{\circ} \mathrm{C}, 160{ }^{\circ} \mathrm{C}, 180{ }^{\circ} \mathrm{C}, 200{ }^{\circ} \mathrm{C}$ ) for $10 \mathrm{~min}$.

The values of WI are shown in Figure 3. The data make evident that at $180{ }^{\circ} \mathrm{C}$, a significant reduction of WI can be observed. Consequently, $160{ }^{\circ} \mathrm{C}$ was chosen as the optimum curing temperature. A comparison of the WI values of TE-30-B-4, GP-30-B-4, and TS-30-B-4 with those of the samples containing pyrogenic silica indicates that at elevated temperatures $\left(180{ }^{\circ} \mathrm{C}\right.$, $200{ }^{\circ} \mathrm{C}$ ), boric acid is more effective in improving WI.

Physico-mechanical properties of
alkoxysilane/boric acid-treated fabrics
To evaluate the physico-mechanical
parameters, cotton specimens were finished with
different treating baths containing a hydrolyzed
alkoxysilane (TEOS, GPTMS or TESP-SA, 15
mol/100 mL and $30 \mathrm{mmol} / 100 \mathrm{~mL})$ in




\section{CHRISTIAN SCHRAMM and ANGELIKA AMANN}

combination with either boric acid or pyrogenic silica. The as-prepared cotton samples were subjected to a curing process at $160{ }^{\circ} \mathrm{C}$ for 10 min. Hence, the physico-mechanical properties were evaluated. The findings for the cotton samples treated with the boric acid-containing solutions are presented in Table 1 . The results for the pyrogenic silica-containing specimens are shown in Table 2.

\section{Add-on}

The add-on values indicate the portions of the finishing agent being attached to the textile substrate. The values in Table 1 and Table 2 make evident that the samples treated with the finishing baths containing $30 \mathrm{mmol} / 100 \mathrm{~mL}$ of alkoxysilane show the highest add-on values. It can be also observed that the TESP-SA treated cotton samples have lower add-on values than the samples finished with TEOS or GPTMS.

Dry crease recovery angle analysis

Textile materials made of cotton tend to form creases, which can only be removed by means of an ironing process. Various chemical agents have been studied to enhance the crease resistance tendency. ${ }^{30-33}$ Due to the demand for substituting harmful chemicals, such as formaldehyde, various novel finishing agents have been studied. ${ }^{34-37}$ To measure the tendency of forming wrinkles, the dry crease recovery angle (DCRA) values were evaluated, indicating the capability of cotton fabrics to recover. The results of the DCRA measurements are given in Table 1 and Table 2.

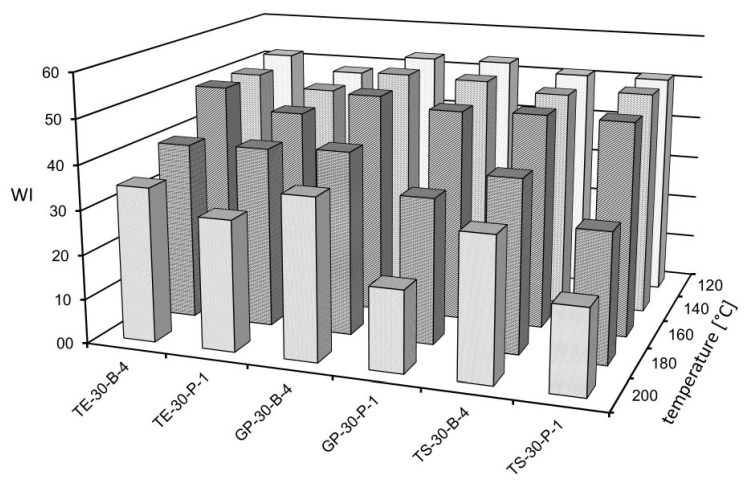

Figure 3: WI of cotton samples thermally treated at different temperatures $\left(120^{\circ} \mathrm{C}, 140{ }^{\circ} \mathrm{C}, 160{ }^{\circ} \mathrm{C}, 180{ }^{\circ} \mathrm{C}\right.$ and 200

${ }^{\circ} \mathrm{C}$ ) for $10 \mathrm{~min}$ for evaluation of the optimum process parameters

Table 1

Physico-mechanical properties of cotton fabrics treated with alkoxysilane/boric acid

\begin{tabular}{|c|c|c|c|c|c|c|}
\hline Sample & $\begin{array}{c}\text { Add-on } \\
(\%)\end{array}$ & $\begin{array}{c}\text { DCRA (w+f) } \\
(\%)\end{array}$ & $\begin{array}{c}\text { Tensile strength } \\
(\%)\end{array}$ & $\begin{array}{l}\text { Flexural rigidity } \\
(\%)\end{array}$ & $\begin{array}{c}\text { Air permeability } \\
(\%)\end{array}$ & $\begin{array}{l}\text { WI } \\
(\%) \\
\end{array}$ \\
\hline$\overline{\mathrm{RM}}$ & & 100.0 & 100.0 & 100.0 & 100.0 & 100.0 \\
\hline RM-B-2 & 1.73 & 146.7 & 80.1 & 101.6 & 69.1 & 96.2 \\
\hline RM-B-4 & 1.78 & 141.7 & 94.8 & 95.5 & 71.0 & 97.0 \\
\hline TE-15-B-2 & 2.75 & 152.3 & 91.8 & 153.3 & 63.5 & 96.1 \\
\hline TE-15-B-4 & 1.11 & 147.0 & 96.3 & 108.4 & 52.8 & 96.1 \\
\hline TE-30-B-2 & 3.37 & 146.0 & 81.9 & 244.1 & 82.0 & 93.7 \\
\hline TE-30-B-4 & 4.47 & 148.2 & 86.0 & 195.6 & 79.8 & 91.8 \\
\hline GP-15-B-2 & 1.78 & 150.4 & 84.4 & 48.9 & 83.3 & 97.8 \\
\hline GP-15-B-4 & 2.78 & 170.8 & 77.8 & 96.5 & 86.7 & 96.9 \\
\hline GP-30-B-2 & 5.52 & 167.3 & 70.1 & 94.1 & 85.0 & 96.6 \\
\hline GP-30-B-4 & 3.77 & 171.0 & 77.7 & 100.9 & 81.1 & 96.3 \\
\hline TS-15-B-2 & 2.47 & 161.7 & 78.6 & 104.1 & 87.6 & 89.3 \\
\hline TS-15-B-4 & 2.22 & 160.0 & 78.0 & 130.2 & 88.8 & 89.0 \\
\hline TS-30-B-2 & 3.68 & 156.8 & 81.4 & 119.1 & 86.7 & 85.5 \\
\hline TS-30-B-4 & 3.15 & 155.0 & 75.3 & 108.7 & 86.5 & 88.1 \\
\hline
\end{tabular}


Table 2

Physico-mechanical properties of cotton fabrics treated with alkoxysilane/pyrogene silica

\begin{tabular}{lcccccc}
\hline & $\begin{array}{c}\text { Add-on } \\
(\%)\end{array}$ & $\begin{array}{c}\text { DCRA }(\mathrm{w}+\mathrm{f}) \\
(\%)\end{array}$ & $\begin{array}{c}\text { Tensile } \\
\text { strength }(\%)\end{array}$ & $\begin{array}{c}\text { Flexural } \\
\text { rigidity }(\%)\end{array}$ & $\begin{array}{c}\text { Air permeability } \\
(\%)\end{array}$ & $\begin{array}{c}\text { WI } \\
(\%)\end{array}$ \\
\hline RM & & 100.00 & 100.00 & 100.00 & 100.00 & 100.00 \\
RM-P-0.5 & 0.67 & 148.40 & 98.5 & 96.55 & 63.09 & 96.0 \\
RM-P-1 & 0.16 & 147.89 & 97.5 & 142.82 & 59.23 & 96.7 \\
TE-15-P-0.5 & 3.21 & 146.04 & 98.9 & 194.72 & 72.10 & 95.5 \\
TE-15-P-1 & 3.05 & 148.06 & 91.8 & 165.47 & 71.24 & 95.3 \\
TE-30-P-0.5 & 3.53 & 133.90 & 96.5 & 376.53 & 98.01 & 92.4 \\
TE-30-P-1 & 5.47 & 141.48 & 83.7 & 397.28 & 84.55 & 99.3 \\
GP-15-P-0.5 & 1.95 & 171.16 & 79.9 & 63.74 & 46.35 & 97.7 \\
GP-15-P-1 & 2.26 & 151.77 & 69.6 & 91.37 & 76.82 & 95.1 \\
GP-30-P-0.5 & 5.74 & 174.87 & 53.8 & 101.75 & 74.89 & 99.1 \\
GP-30-P-1 & 5.81 & 163.91 & 74.9 & 95.73 & 69.74 & 87.0 \\
TS-15-P-0.5 & 3.14 & 175.55 & 59.5 & 106.75 & 48.28 & 87.5 \\
TS-15-P-1 & 2.12 & 151.77 & 75.0 & 104.30 & 53.65 & 86.1 \\
TS-30-P-0.5 & 3.42 & 152.45 & 44.8 & 119.93 & 75.97 & 85.6 \\
TS-30-P-1 & 3.23 & 150.76 & 81.2 & 82.51 & 70.82 & 87.9 \\
\hline
\end{tabular}

A comparison of the DCRA values reveals that an increase in crease resistance can be observed for the cotton samples that were treated with GP (GP-30-B-2, GP-15-B-4, GP-30-B, GP-30-P-1, GP-15-P-0.5, GP-30-P-0.5). When TESP-SAbased formulations were used, the DCRA values increased significantly by $50 \%$ to $60 \%$. However, these formulations are not able to reach the performance level of the formaldehyde-releasing durable press agent dimethyoldihydroxyethyleneurea (DMDHEU) or the formaldehydefree 1,2,3,4-butanetetracarboxylic acid (BTCA). ${ }^{38}$

\section{Tensile strength}

The values of the tensile strength (TS) measurements performed for the boric acid-based specimens are shown in Table 1 and those for the pyrogenic silica-based specimens are presented in Table 2. The findings make evident that, compared to the untreated fabric, in all cases a reduction of the TS values can be observed. This phenomenon is ascribed to the fact that the finishing of the cotton fabrics results in the formation of crosslinking and therefore restricts the relative mobility of the cellulose chains. Consequently, the distribution of stress cannot be equalized on the individual cellulosic chains. The highest loss in TS can be observed for the GPTMS- and TESP-SA-treated cotton fabrics. The results of the reduction of the TS values are consistent with those found in previous studies relating to durable press finishing of cotton. ${ }^{9,39}$

\section{Flexural rigidity}

Chemical treatment of cellulosic fabrics influences their stiffness, which contributes to the sensory perception of a fabric. ${ }^{40,41}$ Stiffness can be described by flexural rigidity (FR). The findings presented in Table 1 reflect that the cotton fabrics that were treated with mixtures containing GP show a moderate decrease in FR, whereas the TEOS-finished samples have significantly increased FR values. These phenomena can be observed for the boric acid-containing samples, as well as for the pyrogenic silica-containing samples. These findings are confirmed by the results of earlier investigations. ${ }^{42,43}$

\section{Abrasion resistance}

Abrasion causes mechanical deterioration of fabric components because of rubbing against another rough surface. This phenomenon depends on the fiber, yarn and construction of the fabric. Since chemical modifications also show a high impact on the abrasion characteristics, the treated fabrics were subjected to an abrasive test. The results are shown in Table 3. The findings reflect that those specimens that were treated with GPTMS, in combination with boric acid, show the best abrasion resistance, whereas the abrasion performance of the TEOS-modified specimens is reduced. The same phenomena have been observed in other studies. ${ }^{44-46}$ 


\section{CHRISTIAN SCHRAMM and ANGELIKA AMANN}

Table 3

Abrasion characteristics of cotton fabrics treated with alkoxysilane/boric acid or alkoxysilane/pyrogene silica

\begin{tabular}{|c|c|c|c|c|c|c|c|c|c|}
\hline \multirow[b]{3}{*}{ Sample } & \multicolumn{9}{|c|}{ Abrasion resistance } \\
\hline & \multicolumn{4}{|c|}{ cycles } & \multirow[b]{2}{*}{ Sample } & \multicolumn{4}{|c|}{ cycles } \\
\hline & $\begin{array}{c}10.000 \\
(\%)\end{array}$ & $\begin{array}{c}20.000 \\
(\%)\end{array}$ & $\begin{array}{c}25.000 \\
(\%)\end{array}$ & $\begin{array}{c}30.000 \\
(\%)\end{array}$ & & $\begin{array}{c}10.000 \\
(\%)\end{array}$ & $\begin{array}{c}20.000 \\
(\%)\end{array}$ & $\begin{array}{c}25.000 \\
(\%)\end{array}$ & $\begin{array}{c}30.000 \\
(\%)\end{array}$ \\
\hline RM & 3.0 & 4.80 & 6.55 & 8.50 & RM & 2.99 & 4.80 & 6.55 & 8.50 \\
\hline RM-B-2 & 7.2 & 9.08 & 9.08 & dest* & RM-P-0.5 & 2.88 & 8.40 & 10.86 & 13.27 \\
\hline RM-B-4 & 4.7 & 10.90 & dest & & RM-P-1 & dest & & & \\
\hline TE-15-B-2 & 3.2 & 7.63 & dest & & TE-15-P-0.5 & 2.04 & 4.81 & 5.34 & 6.42 \\
\hline TE-15-B-4 & dest & & & & TE-15-P-1 & 1.86 & 4.28 & 4.89 & 5.40 \\
\hline TE-30-B-2 & dest & & & & TE-30-P-0.5 & 1.36 & dest & & \\
\hline TE-30-B-4 & 2.1 & 4.22 & 5.65 & 7.07 & TE-30-P-1 & dest & & & \\
\hline GP-15-B-2 & 1.0 & 4.09 & 5.76 & 7.86 & GP-15-P-0.5 & 1.29 & 5.22 & 7.61 & 10.93 \\
\hline GP-15-B-4 & 0.7 & 3.04 & 4.12 & 5.89 & GP-15-P-1 & 1.56 & 5.36 & 7.48 & 9.85 \\
\hline GP-30-B-2 & 1.2 & 4.54 & 6.81 & 9.88 & GP-30-P-0.5 & 3.31 & 6.38 & dest & \\
\hline TESP-SA & 0.9 & 2.40 & 4.12 & 5.78 & GP-30-P-1 & 3.06 & 5.88 & 6.00 & 10.11 \\
\hline TS-15-B-2 & 1.9 & 5.57 & 6.32 & & TS-15-P-0.5 & 4.20 & 8.90 & dest & \\
\hline TS-15-B-4 & 3.1 & 7.41 & dest & & TS-15-P-1 & dest & & & \\
\hline TS-30-B-2 & 0.3 & 3.23 & 6.41 & 7.90 & TS-30-P-0.5 & 2.20 & 7.23 & 8.22 & 10.43 \\
\hline TS-30-B-4 & 1.2 & 4.55 & dest & & TS-30-P-1 & dest & & & \\
\hline
\end{tabular}




\section{Air permeability}

The air permeability is of importance for the end use of various fabrics, such as wind resistance, and is characterized by the air volume that is passed through a specified area in a specified period under a pressure gradient. It depends on different geometrical and structural factors of the textile material, such as fiber diameter, fiber cross section, and fabric thickness. Since the air flow takes place through the interstices of the yarn, a surface modification can also influence the air permeability, because of changing the interyarn pore space. The findings are presented in Table 1 and Table 2, and reveal that the incorporation of boric acids leads to a significant decrease in the air permeability when TE was used. In the case of TESP-SA-containing samples, only a moderate decrease can be observed. The reverse effect is obtained when pyrogenic silica was applied.

\section{Whiteness index}

Chemical modifications of cotton fabrics are usually associated with the thermal treatment of the impregnated fabric in an attempt to obtain durable adhesion of the chemical agent. This thermal treatment at elevated temperatures results in an undesired yellowing of the textile substrate, which is caused by the formation of unsaturated conjugated groups and hence reduces the WI. ${ }^{47}$

The findings of the WI evaluation are shown in Table 1 and Table 2, and reveal that the values of the WI are reduced to $15 \%$, compared to the untreated fabric. The highest reduction of the WI values can be observed for the samples that were treated with TESP-SA. This observation can be explained by the fact that the succinic acid group is more inclined to form conjugated unsaturated groups. $^{36}$

\section{Water vapor permeability}

The ability of a textile material to be permeable for vapor is an important property for wear comfort, since it allows sweat to be transported away from the skin. This moisture management (transport of both moisture vapor and liquid away from the body) is influenced by a variety of structural and chemical characteristics of the fabric.

Therefore, the water vapor permeability (WVP) was evaluated. Figure 4 shows the WVP of the alkoxysilane/boric acid-finished (Fig. 4a) and the alkoxysilane/pyrogenic silica-treated (Fig. 4b) cellulosic fabrics, compared to the raw material. One can observe that the chemical treatment of the cotton fabrics results in an increase in the WVP when an alkoxysilane is present. The incorporation of boric acid solely or pyrogenic silica does not cause a significant effect on the WVP.

\section{Morphology of the surface}

The morphological structure of the treated cotton samples was studied by means of confocal laser microscopy. Figure 5 shows the images of RM-B-4 (Fig. 5a), RM-P-1 (Fig. 5b), TE-30-B-4 (Fig. 5c), TE-30-P-1 (Fig. 5d), GP-30-B-4 (Fig. 5e), GP-30-P-1 (Fig. 5f), TS-30-B-4 (Fig. 5g), and TS-30-P-1 (Fig. 5h).
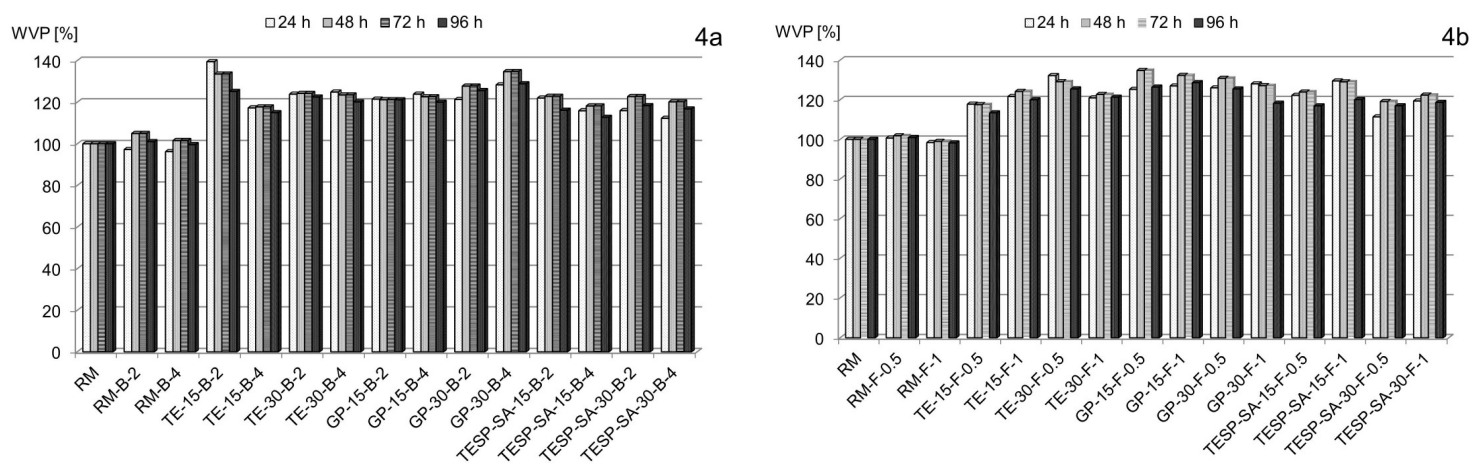

Figure 4: Water vapor permeability of cotton fabrics treated with alkoxysilane/boric acid (a) and alkoxysilane/pyrogenic silica (b) 

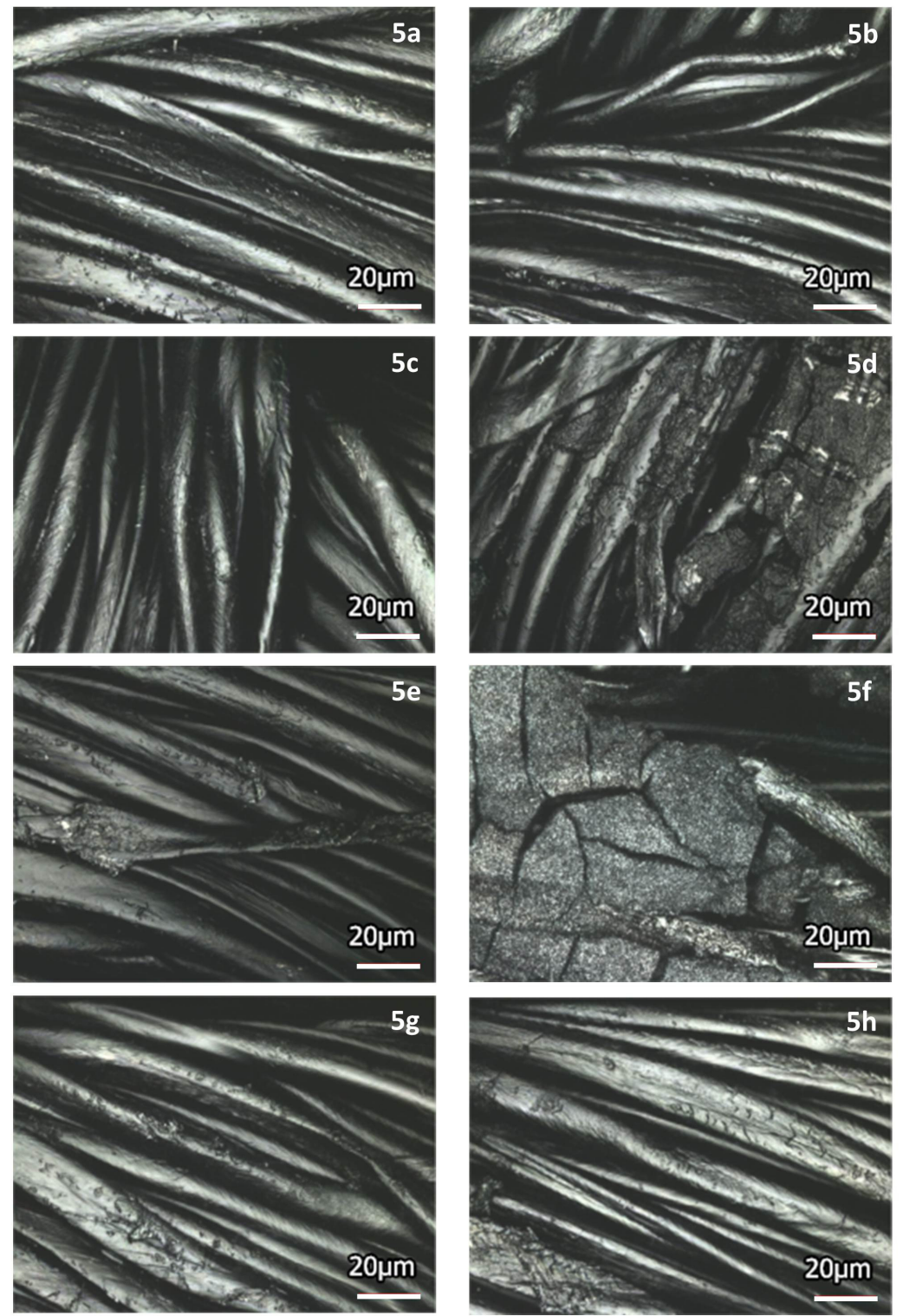

Figure 5: Confocal laser microscope images of RM-B-4 (a), RM-P-1 (b), TE-30-B-4 (c), TE-30-P-1 (d), GP-30-B-4 (e), GP-30-P-1 (f), TS-30-B-4 (g), and TS-30-P-1 (h)

Figure $5 \mathrm{a}$ and $5 \mathrm{~b}$ make evident that no significant modification of the surfaces can be observed when the cotton specimens were treated with boric acid and pyrogenic silica. The application of TEOS, in combination with pyrogenic silica, results in the formation of deposits, as can be seen in Figure 5d. When GPTMS is used in combination with pyrogenic silica, this phenomenon is intensified, as shown in Figure 5f. No deposits can be observed when TESP-SA was used in conjunction with boric acid (Fig. 5g). However, the incorporation of pyrogenic silica gives rise to the observation of deposits on the fabric surface (Fig. 5h).

Thus, it can be concluded that the hydrolyzed alkoxysilanes and the water-soluble boric acid penetrate into the interstices between the cellulose chains, where they can react with the hydroxyl groups of the cellulose at elevated temperatures. On the other hand, pyrogenic silica is insoluble in water and consequently is capable of forming solid aggregates with the alkoxysilanes, which are deposited on the fabric surface, as can be observed in Figure 5d, Figure 5f and Figure 5h. 


\section{FT-IR analysis}

Figure 6 shows the spectra of RM (Fig. 6a), RM-B-4 (Fig. 6b), RM-P-1 (Fig. 6c), TE-30-B-4 (Fig. 6d), TE-30-P-1 (Fig. 6e), GP-30-B-4 (Fig. 6f), GP-30-P-1 (Fig. 6g), TS-30-B-4 (Fig. 6h), and TS-30-P-1 (Fig. 6i). The vibration modes in the region from $850 \mathrm{~cm}^{-1}$ to $1200 \mathrm{~cm}^{-1}$ can be assigned to the absorption bands of cotton (C-O stretching vibration, $1028 \mathrm{~cm}^{-1}$; symmetric C-O-C band, $910 \mathrm{~cm}^{-1}$, asymmetric $\mathrm{C}-\mathrm{O}-\mathrm{C}$ band, 1155 $\left.\mathrm{cm}^{-1}\right)$. The asymmetric stretching vibrations of Si$\mathrm{O}-\mathrm{Si}\left(1080 \mathrm{~cm}^{-1}\right)$ and $\mathrm{Si}-\mathrm{OH}\left(880 \mathrm{~cm}^{-1}\right)$ are also located in this region. ${ }^{48} \mathrm{~A}$ noteworthy aspect of the spectra in Figure of (GP-30-B-4) and Figure 6h (GP-30-P-1) is that no absorption band can be observed at $1255 \mathrm{~cm}^{-1}$, indicating that no epoxide ring stemming from unreacted GPTMS is present. The inspection of the spectra of TS-30-B-4 (Fig. 6h) and TS-30-P-1 (Fig. 6i) make evident that an absorption band appears at $1715 \mathrm{~cm}^{-1}$, which is attributed to the stretching vibration of the carboxyl carbonyl group of TESP-SA. In Figure $6 \mathrm{~h}$ and Figure 6i, a weak band can also be observed at $1786 \mathrm{~cm}^{-1}$, which can be assigned to the symmetric vibration mode of the carboxyl carbonyl group of a five-membered cyclic anhydride unit. The corresponding band of the asymmetric carboxyl carbonyl vibration at 1860 $\mathrm{cm}^{-1}$ is too weak to be detected. ${ }^{49}$ The absorption band at $2982 \mathrm{~cm}^{-1}$ is due to the $-\mathrm{CH}_{2}$ - stretching vibrations. The broad vibration bands located in the spectral region from $3100 \mathrm{~cm}^{-1}$ to $3600 \mathrm{~cm}^{-1}$ are assigned to hydrogen-bonded $\mathrm{O}-\mathrm{H}$ stretching absorptions. The $\mathrm{O}-\mathrm{H}$ vibration modes that are located at wavenumbers higher than $3400 \mathrm{~cm}^{-1}$ are contributed to intramolecular hydrogen bonds, whereas the wavenumbers lower than $3400 \mathrm{~cm}^{-1}$ are due to intermolecular hydrogen bonds, indicating that the H-bonding system is not involved in the interaction of the cellulose with the reagents. ${ }^{50,51}$ According to the literature, the stretching vibration of the $\mathrm{B}-\mathrm{O}$ bond should appear in the region from $1300 \mathrm{~cm}^{-1}$ to $1500 \mathrm{~cm}^{-}$ ${ }^{1}{ }^{52,53}$ However, a comparison of the spectrum of RM (Fig. 6a) with the spectra of RM-B-4 (Fig. 6b), TE-30-B-4 (Fig. 6d), GP-30-B-4 (Fig. 6f), and TS-30-B-4 (Fig. 6h) reveals that no difference can be observed in this region.

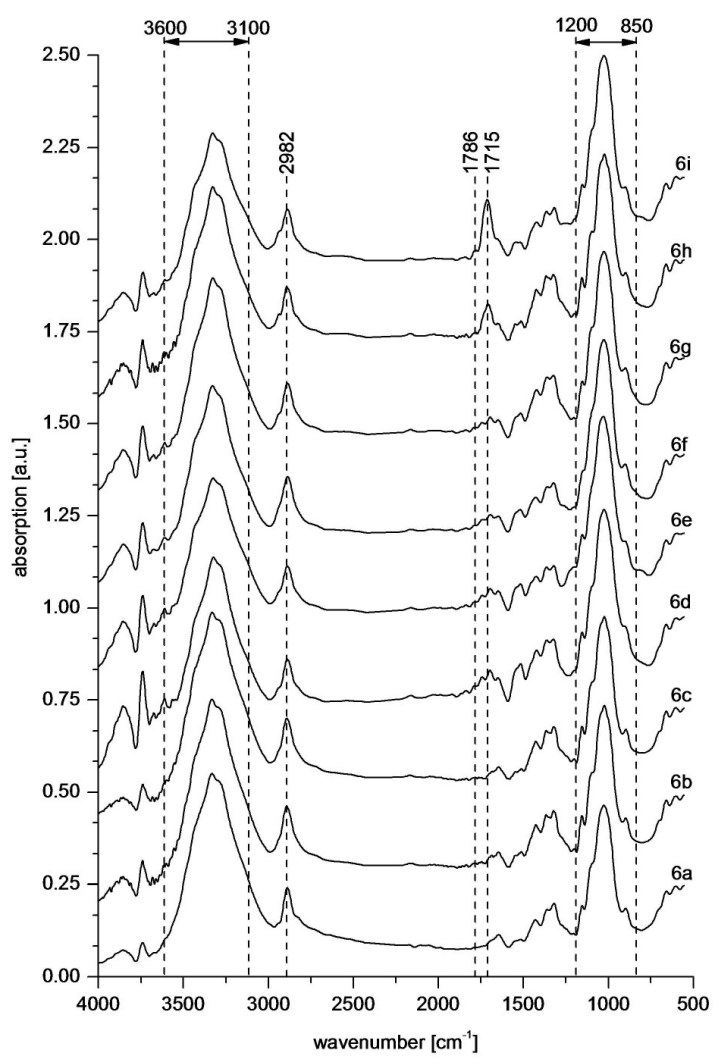

Figure 6: FT-IR spectra of RM (a), RM-B-4 (b), RM-P-1 (c), TE-30-B-4 (d), TE-30-P-1 (e), GP-30-B-4 (f), GP-30-P-1 (g), TS-30-B-4 (h), and TS-30-P-1 (i) 


\section{CHRISTIAN SCHRAMM and ANGELIKA AMANN}

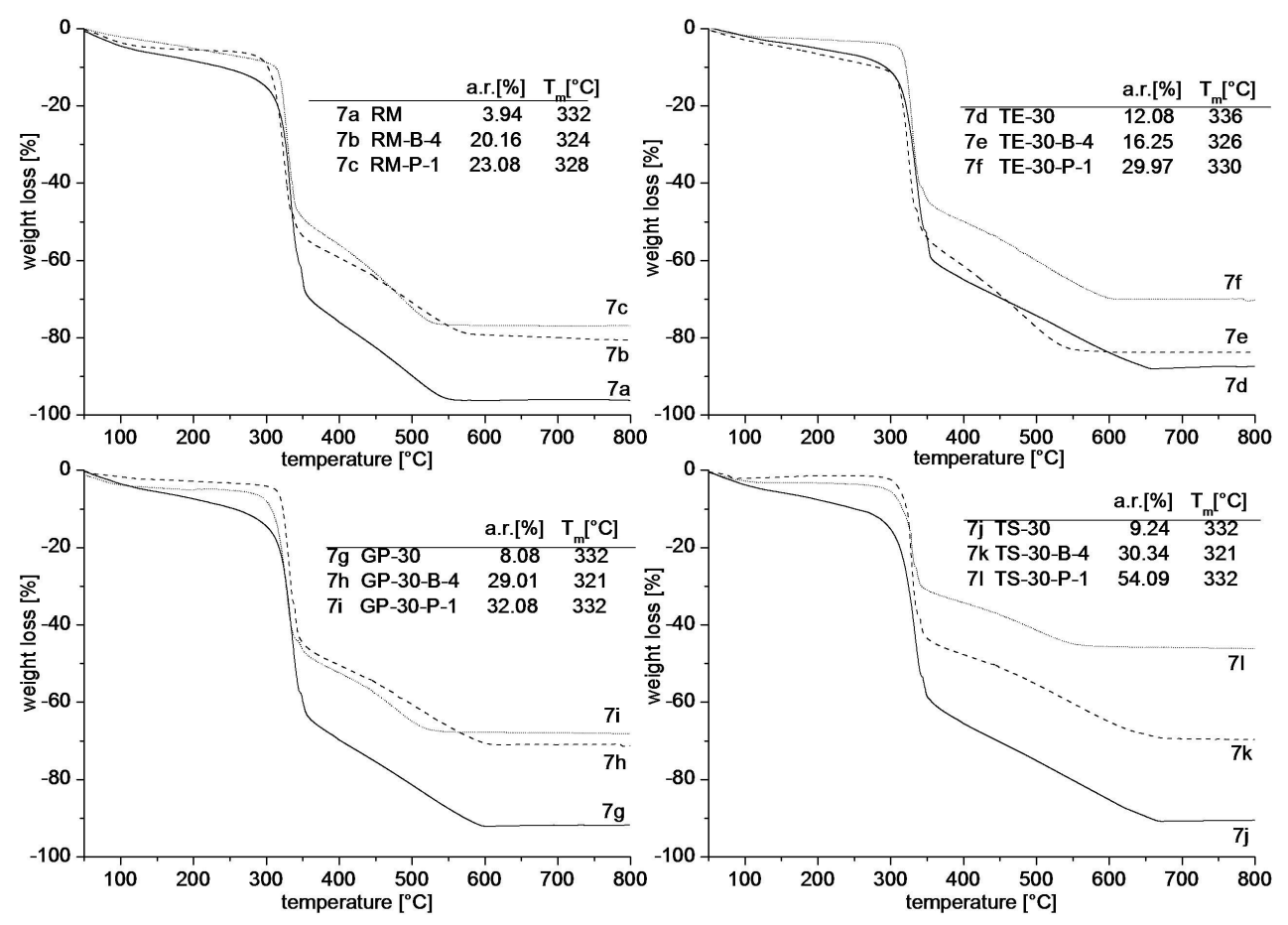

Figure 7: TGA curves of RM (7a), RM-B-4 (7b) and RM-P-1 (7c), TE-30 (7d), TE-30-B-4 (7e), TE-30-P-1 (7f), GP-30 (7g), GP-30-B-4 (7h), GP-30-P-1 (7i), TS-30 (7j), TS-30-B-4 (7k), TS-30-P-1 (7l)

\section{Thermogravimetric analysis}

Cellulosic materials are known to undergo thermal degradation via different processes, such as depolymerisation, chain scission, oxidation, dehydration or decarboxylation. Therefore, the thermal behavior of the chemically modified specimens was investigated by means of TGA.

Figure 7 presents the TGA curves of RM (Fig. 7a), RM-B-4 (Fig. 7b), RM-P-1 (Fig. 7c), TE-30 (Fig. 7d), TE-30-B-4 (Fig. 7e), TE-30-P-1 (Fig. 7f), GP-30 (Fig. 7g), GP-30-B-4 (Fig. 7h), GP-30P-1 (Fig. 7i), TS-30 (Fig. 7j), TS-30-B-4 (Fig. 7k), and TS-30-P-1 (Fig. 71). The curves make evident that up to $300{ }^{\circ} \mathrm{C}$, a moderate weight loss can be observed. The temperature at which the highest rate of decomposition can be observed lies between $320{ }^{\circ} \mathrm{C}$ and $340{ }^{\circ} \mathrm{C}$. Significant differences can be observed in terms of the ash residue (a.r.) As expected, RM shows the lowest residue $(3.94 \%)$, whereas RM-B-4 $(20.16 \%)$ and RM-P-1 (23.08\%) have higher ash residues. The values of the ash residue increased when the cotton specimens were treated with siliconecontaining recipes. Thus, an ash residue of $12 \%$ was obtained in the case of TE-30. The highest values were obtained for TS-30-B-4 and TS-30-P1.

\section{CONCLUSION}

A cotton-based material was chemically modified with solutions containing an alkoxysilane (TEOS, GPTMS, TESP-SA) in combination with boric acid or pyrogenic silica. The measurements of the physico-mechanical properties reveal that an increase in the DCRA values can be observed, when the samples were treated with GPTMS or TESP-SA-containing finishing baths. A reduction of the tensile strength, flexural rigidity and of the WI can be observed. The application of TEOS results in an enhancement of the air permeability. The water vapor permeability is increased. A comparison with the results of the study in which cotton samples were modified by means of alkoxysilanes in combination with polymers reveals that the DCRA values and the WI values reach almost the same level, whereas the tensile strength suffers moderate reduction. ${ }^{29}$

The coating process with alkoxysilanes in combination with specific additives is of high interest for industrial purposes, since this technique enables the tailoring of the surface properties of cellulose based materials. 
ACKNOWLEDGMENTS: The authors gratefully acknowledge the FFG (Österreichische Forschungsförderungs-gesellschaft) for financial support of the project 846932 (Endowed Professorship in Advanced Manufacturing). The authors would like to thank the Testing Institute of HTL Dornbirn (Austria) for the use of their facilities.

\section{REFERENCES}

1 R. J. Moon, A. Martini, J. Nairn, J. Simonsen and J. Youngblood, Chem. Soc. Rev., 40, 3941 (2011), https://doi.org/10.1039/C0CS00108B

2 J. F. Kadla and G. Richard, Cellulose Chem. Technol., $\quad 34, \quad 197 \quad$ (2000), http://www.cellulosechemtechnol.ro/onlinearticles.php

C. Schramm, B. Rinderer, W. Binder, R. Tessadri and H. Duelli, in "Recent Research Developments in Applied Polymer Science", vol. 3, edited by S. G. Pandalai, Research Signpost, 2006, pp. 37, http://www.ressign.com/UserBookDetail.aspx?bkid=4 $75 \&$ catid $=135 \#$

4 L. L. Hench and J. K. West, Chem. Rev., 90, 33 (1990), https://doi.org/10.1021/cr00099a003

C. J. Brinker and G. W. Scherer, "Sol-Gel Science. The Physics and Chemistry of Sol-Gel Processing", Academic Press, San Diego, 1990, https://doi.org/10.1002/adma.19910031025

6 G. Kickelbick (Ed.), "Hybrid Materials: Synthesis, Characterization, and Applications", Wiley-VCH, Weinheim, Germany, 2007 , https://www.wiley.com/en-

us/Hybrid+Materials\%3A+Synthesis\%2C+Characteriz ation\%2C+and+Applications-p-9783527312993

7 C. Schramm and B. Rinderer, Cellulose, 22, 2811 (2015), https://doi.org/10.1007/s10570-015-0664-5

8 C. Schramm and A. Amann, Cellulose, 26, 4641 (2019), https://doi.org/10.1007/s10570-019-02391-3

9 C. Schramm, Indian J. Fibre Text. Res., 44, 83 (2019),

http://nopr.niscair.res.in/handle/123456789/46458

10 S.-M. Shang, Z. Li, Y. Xing, J. H. Xin and X.-M. Tao, Appl. Surf. Sci., 257, 1495 (2010), https://doi.org/10.1016/j.apsusc.2010.08.081

11 K. L. Xie, X. Liu and Y. L. Zhang, J. Appl. Polym. Sci., $\quad 118, \quad 1872 \quad$ (2010), https://doi.org/10.1002/app.32577

12 S. Brzezinski, D. Kowalczyk, B. Borak, M. Jasiorski and A. Tracz, J. Appl. Polym. Sci., 125, 3058 (2012), https://doi.org/10.1002/app.36353

13 D. Zhang, B. L. Williams, S. B. Shrestha, Z. Nasir, E. M. Becher et al., J. Colloid Interface Sci., 505, 892 (2017), https://doi.org/10.1016/j.jcis.2017.06.087

14 H. Wang, J. Ding, Y. Xue, X. Wang and T. Lin, J. Mater. Res., 25, $1336 \quad$ (2010), https://doi.org/10.1557/JMR.2010.0169
15 G. Rosace, A. Castellano, V. Trovato, G. Iacono and G. Malucelli, Carbohyd. Polym., 196, 348 (2018), https://doi.org/10.1016/j.carbpol.2018.05.012

16 J. Alongi, J. Tata and A. Frache, Cellulose (Dordrecht, Neth), 18, $179 \quad$ (2011), https://doi.org/10.1007/s10570-010-9473-z

17 S. Wang, X. Sui, Y. Li, J. Li, H. Xu et al., Polym. Degrad. Stabil., 128, $22 \quad$ (2016), https://doi.org/10.1016/j.polymdegradstab.2016.02.009 18 P. Pisitsak and U. Ruktanonchai, Text. Res. J., 85, 949

(2015),

https://doi.org/10.1177/0040517514557310

19 R. Poli, C. Colleoni, A. Calvimontes, H. Polášková, V. Dutschk et al., J. Sol-Gel Sci. Technol., 74, 151 (2015), https://doi.org/10.1007/s10971-014-3589-9

20 B. Mahltig, H. Haufe and H. Boettcher, J. Mater. Chem., 15, 4385 (2005), https://doi.org/10.1039/b505177k

21 D. Stular, J. Vasiljevic, M. Colovic, M. Mihelcic, J. Medved et al., J. Sol-Gel Sci. Technol., 83, 19 (2017), https://doi.org/10.1007/s10971-017-4382-3

22 M. Catauro, D. Verardi, D. Melisi, F. Belotti and P. Mustarelli, J. Appl. Biomater. Biomech., 8, 42 (2010), https://doi.org/10.1177/228080001000800107

23 R. Paul, L. Bautista, M. De la Varga, J. M. Botet, E. Casals et al., Text. Res. J., 80, 454 (2010), https://doi.org/10.1177/0040517509342316

24 X. Peng, W. Wei and C. Shui-Lin, AATCC Rev., 5, 28 (2005), https://www.aatcc.org/pub/aatcc-review/

25 B. Xu, J. Ding, L. Feng, Y. Ding, F. Ge et al., Surface Coat. Technol,, 262, 70 (2015), https://doi.org/10.1016/j.surfcoat.2014.12.017

26 E. Pakdel and W. A. Daoud, J. Colloid Interface Sci., 401, 1 (2013), https://doi.org/10.1016/j.jcis.2013.03.016

27 E. Pinho and G. Soares, J. Mater. Chem. B, 6, 1887 (2018), https://doi.org/10.1039/C8TB00052B

28 A. Khani and N. Talebian, J. Coat. Technol. Res., 14, 651 (2017), https://doi.org/10.1007/s11998-0169870-9

29 C. Schramm and A. Amann, Cellulose Chem. Technol., $\quad 53, \quad 347 \quad$ (2019), https://doi.org/10.35812/CelluloseChemTechnol.2019. 53.35

30 K. S. Huang, Y. H. Nien, K. C. Hsiao and Y. S. Chang, J. Appl. Polym. Sci., 102, 4136 (2006), https://doi.org/10.1002/app.24246

31 V. A. Dehabadi, H. J. Buschmann and J. S. Gutmann, Text. Res. J., 83, 1974 (2013), https://doi.org/10.1177/0040517513483857

32 P. Bajaj, J. Appl. Polym. Sci., 83, 631 (2002), https://doi.org/10.1002/app.2262

${ }^{33}$ T. Harifi and M. Montazer, Carbohyd. Polym., 88, 1125

(2012),

https://doi.org/10.1016/j.carbpol.2012.02.017

34 C. M. Welch, Rev. Prog. Color., 22, 32 (1992)

35 C. Schramm, B. Rinderer and R. Tessadri, Carbohyd. Polym., 105, $81 \quad$ (2014), https://doi.org/10.1016/j.carbpol.2014.01.063 


\section{CHRISTIAN SCHRAMM and ANGELIKA AMANN}

36 B. Arık, O. Avinc and A. Yavas, Cellulose, 25, 4841 (2018), https://doi.org/10.1007/s10570-018$1885-1$

37 B. Arık, A. Yavaș and O. Avinc, Fibres Text. East Eur., 25, $106 \quad$ (2017), https://doi.org/10.5604/01.3001.0010.1698

38 C. M. Welch, Am. Dyestuff Rep., 83, 19 (1994)

39 W. L. Xu and Y. Li, Text. Res. J., 70, 957 (2000), https://doi.org/10.1177/004051750007001104

40 N. J. Abbott, Text. Res. J., 21, 435 (1951), https://doi.org/10.1177/004051755102100610

41 M. E. Yüksekkaya, T. Howard and S. Adanur, Tekst. Konfeksiyon, 4, 263 (2008), https://dergipark.org.tr/en/download/articlefile $/ 218073$

42 M. Luo, X. Zhang and S. Chen, Color. Technol., 119, 297 (2003), https://doi.org/10.1111/j.14784408.2003.tb00187.xl

43 Y. J. Yin and C. X. Wang, Mater. Res. Innovat., 13, 41 (2009), https://doi.org/10.1179/143307509X402174

44 C. Schramm, W. H. Binder, R. Tessadri and H. Duelli, Cellulose Chem. Technol., 39, 303 (2005), http://www.cellulosechemtechnol.ro/onlinearticles.php
45 M. R. Plutino, C. Colleoni, I. Donelli, G. Freddi, E. Guido et al., J. Colloid Interface Sci., 506, 504 (2017), https://doi.org/10.1016/j.jcis.2017.07.048

46 C. Colleoni, I. Donelli, G. Freddi, E. Guido, V. Migani et al., Surface Coat. Technol., 235, 192 (2013), https://doi.org/10.1016/j.surfcoat.2013.07.033

47 M. Albeck, A. Ben-Bassat and M. Lewin, Text. Res. J., 35, 935 (1965), https://doi.org/10.1177/004051756503501011

${ }^{48}$ Q. Wang, X. Fan, W. Gao and J. Chen, Carbohyd. Res., $\quad 341, \quad 2170 \quad$ (2006), https://doi.org/10.1016/j.carres.2006.04.048

49 C. Q. Yang, Text. Res. J., 71, 201 (2001), https://doi.org/10.1177/004051750107100303

50 T. Kondo and C. Sawatari, Polymer, 31, 293 (1996), https://doi.org/10.1016/0032-3861(96)82908-9 51 T. Kondo, Cellulose, 4, 281 (1997), https://doi.org/10.1023/A:1018448109214

52 D. Peak, G. W. Luther and D. L. Sparks, Geochim. Cosmochim. Acta, 67, $2551 \quad$ (2003), https://doi.org/10.1016/S0016-7037(03)00096-6

53 G. D. Soraru, F. Babonneau, C. Gervais and N. Dallabona, J. Sol-Gel Sci. Technol., 18, 11 (2000), https://doi.org/10.1023/A:1008733511697 